\title{
Developing a Choice-Based Digital Fiction for Body Image Bibliotherapy
}

\author{
Christine Wilks ${ }^{1 *}$, Astrid Ensslin ${ }^{2}$, Carla Rice ${ }^{3}$, Sarah Riley ${ }^{4}$, Megan Perram ${ }^{5}$, \\ K. Alysse Bailey ${ }^{3}$, Lauren Munro ${ }^{3}$ and Hannah Fowlie ${ }^{3}$
}

${ }^{1}$ Independent Researcher, Leeds, United Kingdom, ${ }^{2}$ Department of Linguistic, Literary and Aesthetic Studies, University of Bergen, Bergen, Norway, ${ }^{3}$ The Re Vision Centre for Art and Social Justice, College of Social and Applied Human Sciences, University of Guelph, Guelph, ON, Canada, ${ }^{4}$ School of Psychology, Massey University, Wellington, New Zealand, ${ }^{5}$ Department of Modern Languages and Cultural Studies, University of Alberta, Edmonton, AB, Canada

OPEN ACCESS

Edited by:

R. Lyle Skains,

Bournemouth University,

United Kingdom

Reviewed by:

Windsor Sherrill,

Clemson University, United States

Peter Cannon,

University of South Florida,

United States

${ }^{*}$ Correspondence:

Christine Wilks

crissxross@gmail.com

Specialty section:

This article was submitted to

Health Communication,

a section of the journal

Frontiers in Communication

Received: 30 September 2021

Accepted: 17 December 2021

Published: 20 January 2022

Citation:

Wilks C, Ensslin A, Rice C, Riley $S$,

Perram M, Bailey KA, Munro $L$ and

Fowlie H (2022) Developing a Choice-

Based Digital Fiction for Body

Image Bibliotherapy.

Front. Commun. 6:786465

doi: $10.3389 /$ fcomm.2021.786465
Body dissatisfaction is so common in the western world that it has become the norm, especially among women and girls. Writing New Body Worlds is a transdisciplinary research-creation project that aims to address these issues by developing an interactive digital fiction for body image bibliotherapy. It is created with the critical codesign participation of a group of young women and non-binary individuals (aged 18-25) from diverse backgrounds, who are representative of its intended audience. This article discusses how our participant research influenced the creative development of the digital fiction, its characters and its novel ludonarrative or story-game design. It theorizes how the specific affordances of a choice-based interactive narrative, that situates the reader-player in the mind of the fictional protagonist, may lead to enhanced empathic identification and agency and, therefore, a more profoundly immersive and potentially transformative experience. This process of "diegetic enactment" is where we postulate the therapeutic value lies: an ontological oscillation between the reader-player's mind and the fictional mind, which may induce the reader-player to reflect upon, and perhaps subtly alter, their own body image.

Keywords: body image, interactive digital narrative, digital fiction, interactive storytelling, bibliotherapy, well-being, feminist participatory action research, critical co-design

\section{INTRODUCTION}

Body image concerns affect the well-being of a generation who are coming of age immersed in our hyper-visual, AI-infused, social and mobile media culture. This is particularly true for young women and non-binary individuals of diverse backgrounds who regularly confront appearance-related pressures. Indeed, in the western world, body dissatisfaction in women and even very young girls has become the norm (Grogan, 2017). Studies have shown that social comparisons are linked to poor body image and poor self-esteem, which can lead to anxiety, overexercising, eating disorders and/or worse (Aparicio-Martinez et al., 2019; de Vries et al., 2019; Hogue and Mills, 2019). A postfeminist sensibility, which is "partly constituted through the pervasiveness of neoliberal ideas" (Gill, 2007, p.164), encourages comparison between women. Within a complex postfeminist consumer culture where appearance becomes a marker of value but, paradoxically, where marketers sell a dizzying array of "correct" and desirable ways to appear, comparison becomes one avenue for women to see-and evaluate--how they are doing appearance. This is intensified in a scopic economy where people are expected to look at and evaluate women's bodies and appearance (Rice, 2014; Dobson, 2015; Riley et al., 2018). When that includes looking at and comparing oneself with digitally enhanced and AI 
generated ideal bodies, it becomes a perfect storm for creating poor body image. Marginalized groups, such as women of color, women from lower socio-economic backgrounds, women with disabilities, queer women, non-binary individuals, wholly or partially woman-identifying individuals, and any intersectional combinations they may represent, are particularly disadvantaged in a media culture that privileges unrealistic "ideal," tall, thin, toned, heteronormative, white, "able" bodies.

Writing New Body Worlds ${ }^{1}$ is an intercontinental project, funded by the Social Sciences and Humanities Research Council of Canada (SSHRC IG 435-2018-1036; see Ensslin et al., 2020). It brings together a team of transdisciplinary researchers in theories of gender and the body, critical psychology, art and social justice, digital media arts, electronic literature, narrative, and digital culture. Our goal is to critically co-design and evaluate an interactive digital fiction for body image bibliotherapy with and for our target group of women and non-binary individuals, aged 18-25, from diverse backgrounds. This article focuses on the creative practice-based research phase of the Writing New Body Worlds project. It discusses the findings of our original participant research, secondary transdisciplinary research and how we are putting theory into practice in the development of the creative artefact. The latter is an interactive digital fiction for bibliotherapy, which our researcher-creator, Christine Wilks, is currently developing as an accessible app for the open web platform (Wilks, 2021).

\section{BIBLIOTHERAPY: AN INTERACTIVE PROCESS}

Bibliotherapy, that is, the practice of reading for mental health and well-being, has a long history. The term was coined in 1916 but the idea has been around since ancient times (for example, Aristotle's discussion of catharsis). In current practice, many different types of texts can be used for bibliotherapy; for example, self-help books, or developmental texts for children and young people. However, our focus is in the area commonly known as creative bibliotherapy, which typically uses novels, poetry, (auto)biographies and, more recently, graphic novels and comics in order to meet diverse needs of various publics (McNicol and Brewster, 2018; Brewster, 2019). Since digital media are popular with our target audience, we wanted to find out what particular qualities of digital fiction might benefit the practice of creative bibliotherapy.

There are a variety of ways to engage in bibliotherapy, for example, with a therapist, in a group, or reading alone. The common denominator is that it is an interactive process stimulated by a text (Fanner and Urquhart, 2008; Hynes, 2018). This suggests that interactive digital narrative could be

${ }^{1}$ Writing New Bodies: Critical Co-design for 21st Century Digital-born Bibliotherapy is the original full project title. Since body image is entangled in socio-political contexts, we came to prefer the title, Writing New Body Worlds, as it better reflects that and the idea of writing spaces into existence where people can feel at home in their bodies. well suited for this purpose. For some bibliotherapists, the key therapeutic interaction is between the participant and the therapist or facilitator:

In effect, the triad of participant-literature-facilitator means that there is a dual interaction: The participant's personal response to the story is important, but dialoguing with the facilitator about that response can lead to a whole new dimension of insight. (Hynes, 2018, p.11).

Dialoguing within a group can also be beneficial; for example, the practice of Shared Reading (The Reader, 2021) and community-based approaches (Brewster and McNicol, 2020). Others engage in a dialogue with the text itself. For instance, Kelda Green conducted research into the therapeutic value of letter-writing to a character in a novel (George Elliot's Silas Marner) and then replying as the fictional character (Green, 2018). She observed the participants "oscillat [ing] between the mind of the characters and their own minds. When readers began to make these leaps beyond just simple, one-way empathy,. it felt cathartic" (Green, 2020). As discussed later, a key feature of our interactive digital narrative involves a similar oscillation between the reader-player's mind and a fictional mind - in effect, dialoguing with the interactive narrative itself.

We frame our interactive digital fiction as a form of creative bibliotherapy mindful of debates concerning the relationship between art and therapy within the interdisciplinary field of disability studies and its sibling field, mad studies ${ }^{2}$. If we approach disability broadly, to mean all bodies and minds that western cultures cast outside concepts of "normal"--from physical and sensory disabilities, to autism/neurodiversities, to mental distresses like eating disorders and body dysmorphia (Rice et al., 2015)--then we must acknowledge these debates as relevant to our project. Disability and mad studies scholars have long pushed against the framing of disability art (art by, with, and for disabled people, see Chandler et al., 2021) as primarily therapeutic due, in part, to the ways that therapy logics tend to individualize collective or shared problems and to presume that individuals seeking out therapy are broken and need to be fixed (Mitchell et al., 2018). Here "art as therapy" discourses domesticate art when they take a reductive approach to art's affective force that subsumes and redirects its cathartic impacts toward cultural imperatives to fit normal or be happy. This discounts the very human experience of living with psychic distresses and the value of representing those struggles in layered, nuanced ways that only art and story can do. While we mobilize the language of creative bibliotherapy, we also want to make space in our project for the inherent wildness of art and

\footnotetext{
${ }^{2}$ An evolving interdisciplinary field, Mad Studies "offers critical inquiry into mental health and madness in ways that foreground the oppression, agency, and perspectives of Mad people, past and present, as well as in diverse cultural contexts, to challenge dominant understandings of "mental illness" (Rice et al., 2018, p.270). Scholars in the field use the terminology "Mad" as a reclaimed word to refer to the experiences of users or former users of mental health services and other people with non-normative ways of thinking and feeling.
} 
story, and for the untameability of its affects and effects, which cannot (and should not) be wholly captured or contained by discourses of therapy, healing, overcoming and cure. Thus we make a case for creating art that helps to move and transform people, whilst also speaking back to scholars and practitioners who consider "art-for-arts-sake" and "art-for-therapy" as discrete, non-overlapping categories (Mitchell et al., 2018).

\section{Identification With Narrative Characters}

According to Jannidis "identification ... involves a variety of aspects: sympathy with a character who is similar to the reader; empathy for a character who is in a particular situation; attraction to a character who is a role model for the reader [But $t$ ]o date, there is no means of integrating all of these factors into a satisfactory theory of identification" (Jannidis, 2013, para. 26). Nevertheless, there is ample scientific, social scientific, and anecdotal evidence that " [i] dentifying with a character can have important effects on the audience's real life beliefs and attitudes" (van Krieken et al., 2017, p.3). Although it is a psychological process rather than a narrative technique, identification is "a consequence of reading that may be precipitated by the use of particular techniques of characterization" (Keen, 2006, p. 216) and "various textual cues and devices" (Jannidis, 2013, para. 26). Our concern is to discuss the particular devices and techniques of characterization employed in our interactive digital narrative to support identification with a character who changes as a consequence of reader-player interaction.

The standard theoretical model of the creativebibliotherapeutic process maintains that an emotional connection between reader and text is established through identification with a character. This produces catharsis ${ }^{3}$ which leads to insight about the reader's situation or condition (Troscianko, 2018; Brewster, 2019). There has been a longstanding assumption "that therapeutic effects are dependent on identification with a character cued by similarity between the reader's and the fictional character's situations" (Troscianko, 2018, p.13). But, in the case of eating disorders, such similarity can have negative effects on readers' "mood, self-esteem, feelings about their bodies, and diet and exercise habits" (Troscianko, 2018, p.2) and can actually make eating disorders worse. This is especially the case where texts operate as pedagogical devices in socializing readers into desiring extreme bodily self-discipline or teaching them disordered food- and weight-related practices. Although we deliberately do not depict eating disorders/ disorder eating practices in our digital fiction, nevertheless, we are thinking carefully about introducing narrative devices that will act as safeguards should we find it necessary For example, a textual intervention that breaks the fourth wall of the narrative to signpost the reader-player to sources of help and/or reroute the branching narrative to a safer path.

However, the process of identification does not rely solely on character-based similarity (Eder et al., 2010). There are other drivers of identification, including the likeability of the character

\footnotetext{
3"Catharsis involves both a powerful emotional component in which strong feelings are felt and expressed, as well as a cognitive component in which the individual gains new insights" (Cherry, 2021, para.5).
}

and, importantly, a range of literary or storytelling viewpoint techniques. Indeed, van Krieken et al. "conceptualize identification as a multidimensional experience of mental enactment that evolves from processes in which the reader takes over the central narrative subject's perspective" (2017, p.5). They distinguish six dimensions of identification spatiotemporal, perceptual, cognitive, moral, emotional, and embodied - which are derived from narrative linguistic cues and "can be empirically tested with neurocognitive methods" (van Krieken et al., 2017, p.8). All six dimensions come into play in our digital fiction for bibliotherapy. The spatiotemporal and perceptual dimensions are powerful but relatively basic aspects of identification, allowing the reader to adopt the fictional character's position in time and space, and see, hear and physically experience things from their perspective. The other dimensions-cognitive, moral, emotional, and embodied-are arguably more consequential when designing a bibliotherapeutic interactive narrative and we will go on to discuss these in more detail later.

\section{Participant Research}

Our project began with a period of critical co-design research with participants representing our target audience of young women and non-binary individuals from diverse backgrounds. In order to create media art and literature that fosters self-compassion and positive body-image, a considerate, balanced and participantinformed approach is needed that takes into account the complex, multi-dimensional nature of affect in narrative media interaction. Equally importantly, it needs to follow the principles of inclusive design (Clarkson, 2003), which encourages equitable access-both materially (in terms of accessible technologies and platforms) and psychosocially (pertaining to users' ability to selfproject and relate to media content in ways that crosscut a variety of identity categories and experiences).

Methodologically, we are using a combination of Feminist Participatory Action Research and Critical Community CoDesign. FPAR is a participatory and action-oriented conceptual and methodological framework that centers gendered power dynamics and women's experiences both theoretically and practically, aiming to empower woman-identified individuals in a variety of ways. It enables a critical understanding of multiple, intersectional perspectives. It works toward inclusion and social change through participatory processes while exposing researchers' own biases and assumptions. Importantly, researchers and participants learn from each other through iterations of critical reflection and re-design.

In spring 2019 we held four workshops in three Canadian cities, with a total of 21 participants. They engaged in a range of communicative activities, such as reflective dialog, and free autonarrative writing (sometimes using third person to talk about themselves at a narrative distance). Participants played digital body-themed fictions made by Wilks, as well as a range of Twine ${ }^{4}$ fictions, to get a feel for the software and its storytelling

${ }^{4}$ Twine is an open-source tool for telling interactive, nonlinear stories - https:// twinery.org/. 
possibilities. They also wrote their own Twine stories as a form of interventionist self-disclosure and as a hypertextual exploration of options they may not usually consciously consider as part of imagining their bodies and the decisions they make about their embodied lives (we tested this therapeutic use of Twine in one of our pilot studies, and it worked well for individual autonarration-see Ensslin et al., 2016). What turned out to be a key element of the workshops was the fact that Wilks was present throughout and engaged with participants as artist, co-facilitator, and software instructor. Together, researchers and participants explored body image matters and shared practical and speculative ideas and strategies for coping, self-compassion, healing and social change. The experience of working with our participants has had a profound influence on Wilks's ability to develop a codesigned digital fiction.

\section{From Participant Research to Creative Implementation}

The participants raised a multitude of issues and themes that could, potentially, be pursued in a digital fiction. Building on the information and experiential insights provided by participants, the research team made connections within and across research sites through the coding of the participant data, which included the transcribed audio recordings of discussions and the participants' writings (for more on this phase of the research, see Ensslin et al., 2020). In an attempt to transmute the resulting diverse and manifold richness into a usable form for a digital fiction, Wilks mapped the concerns and themes identified onto various feminist theories to see if a configuration emerged that would lend itself to interactive storytelling. As a structuring guide, she found Sandra Bartky's three categories of disciplinary practice particularly useful: body size and shape; movement, gesture and posture; and the body as ornamented surface. Following Foucault, Bartky argues that these disciplinary practices produce "docile bodies" that are recognizably feminine through the process of internalizing norms (Bartky, 1988). Judith Butler's notion of performing gender identity (Butler, 1997) also resonated with the participant data. In terms of narrative content and the therapeutic brief, she looked for guidance from evidence-based and feminist body image therapy methodologies (Cash, 2008; Grogan, 2017; O’Connor et al., 2017; Orbach, 2019; Kite and Kite, 2020). Nevertheless, the participants' own stories and memories offered the most fertile ground for the creative fiction-making process. The coded transcriptions of the workshop discussions provide valuable corroborating and amplifying support.

Character-based short form narratives, including digital fictions, often work best with only one protagonist. We had hoped that an idea of the main character would surface during the participant workshops but they offered such a vibrant mix of voices, memories, experiences and stories that Wilks, regarding character as a representation of viewpoint, came away pondering how to distil all these different points of view into a single protagonist. Her first impulse was to propose a world of four stories, each with a different body image theme. However, when she began working on what was to be the first story, on the theme of body size and shape, more characters emerged who began to interject with their own stories or viewpoints. Rather than stick to her initial plan, Wilks allowed these stories to fold into and expand the main story. Later, it struck her that this change was apposite because, in many ways, it mirrored the social experience of the participant workshops.

\section{Characterization, Story and Interactivity}

The protagonist of the digital fiction, and its focalizing character whose perspective the reader-player shares, is called Hayley. It quickly becomes evident from her negative self-talk that Hayley has body image issues relating to her size and shape. The interactive narrative traces her daily life-working, eating, commuting, interacting with social media, socializing with friends, spending solitary time at home-a cycle that repeats with variations. Throughout, Hayley struggles with competing internal and external voices, influencing how she behaves, thinks and feels. During a key scene at a house party with a group of friends, a mirror shatters and Hayley (erroneously) feels responsible. The incident stimulates a collective sharing of body-image-related observations, memories and feelings as the friends pick up the pieces. These story fragments, speculations and arguments, that pierce, extend and complicate the main narrative (not least because of the effect they have on Hayley), were inspired by the personal stories and experiences shared during the participant workshops. However, being fiction, Wilks inserted some other, more polarized, voices and viewpoints for dramatic (and therapeutic) purposes. This assemblage dramatizes the affective network of kinship of the participant workshops and, because the narrative is interactive and choice-based, the network incorporates the reader-player in a concrete way.

Although the work is text-based, Wilks conceives it as a drama because there is no (global) narrator, no single highest level speech position from which the whole narrative discourse originates. All of the characters speak for themselves, like actors in a play. In the case of the protagonist, her interior dialogue of conflicting hyper-critical and more supportive voices (e.g., her Inner Critic and Inner Ally) is also dramatized. Thus Hayley becomes "a posthuman collectivity, an "I" transformed into the "we" of autonomous agents operating together to make a self" (Hayles, 1999, p.6) and, crucially, one of these agents is the reader-player. As an interactive protagonist, Hayley is the character or point of view that the reader plays by making meaningful choices on her behalf. These choices, embedded as they are in a diegetic ${ }^{5}$ feedback loop, can affect Hayley's body image, raising or lowering her levels of body dissatisfaction. This, in turn, affects narrative progress. At these decision moments, especially, the protagonist and the engaged reader-player become one. For the purposes of this paper, we will call this blended or entangled posthuman entity, the reader-playing-as-Hayley. Situating the reader-player in the mind of the protagonist may lead to enhanced empathic

\footnotetext{
${ }^{5}$ Diegetic elements are part of the storyworld and therefore can be perceived by the fictional characters; whereas non-diegetic or extra-diegetic elements do not exist within the storyworld and therefore can only be perceived by the audience/reader/ player-e.g., the music soundtrack in a film or user interface elements in a game.
} 
identification and agency and, therefore, a profoundly immersive and potentially transformative experience. This process of "diegetic enactment" (Wilks, 2020, p.24) is where we postulate the therapeutic value lies: an ontological oscillation between the reader-player's mind and the fictional mind, which may induce the reader-player to reflect upon, and perhaps subtly alter, their own body image. This hypothesis is supported by research using neuroimaging (fMRI) techniques which suggests "that conscious attempts to adopt another person's perspective may prompt perceivers to consider that person via cognitive processes typically reserved for introspection about the self" (Ames et al., 2008, p.643). In thinking through Hayley's options, making decisions for her and experiencing the consequences of those choices, the reader-playing-as-Hayley will be identifying with her in powerful multidimensional ways with cathartic potential. In addition to spatiotemporal and perceptual identification, the reader-player shares the protagonist's thoughts, intentions and expectations (cognitive identification); they share her beliefs, goals and values (moral identification); they share her affective responses (emotional identification); and they share her body image (embodied identification) (van Krieken et al., 2017, p.7-9). The combined effect is that the reader-player takes on "another person's perspective, [and in doing so] comes to treat that person as more 'selflike" (Ames et al., 2008, p.642).

\section{Ludonarrative Design and the Docile Body}

During the research workshops it became clear that participants wanted to resist the pressures of our hyper-visual culture and its scopic economy, which contributes to so much body dissatisfaction. Collectively, we decided to avoid graphic, mimetic representations of the body. Therefore, there is no avatar, the digital fiction is text-based but full of bodies constructed textually by the reader-player from the dynamic onscreen lexia.

Nevertheless, in a digital fiction, visual language is important. All the speaking characters, including Hayley's inner voices, are represented by distinctive "voice-bubbles," differentiated by shape and color. During scenes where Hayley is alone or preoccupied with her own thoughts, she is also represented by an abstract animated curvilinear freeform shape, which Wilks calls an "organic" (when writing digitally, it is crucial to name entities so that they can be addressed in/by code). Animation brings the organic to life, suggesting some kind of embodied subjectivity, behavior, bodily characteristics and/or emotional responses. Abstraction leaves the organic open to interpretation and its signification fluid, thus removing some potential barriers to identification predicated on appearancebased similarity. In short, the organic represents Hayley's bodymind in close-up. Following disability studies scholars Price (2015) and Clare (2017), we use the phrase "bodymind" to overcome problems with the mind/body split in western thought that treats the mind and body as distinct entities (Rice et al., 2020). In conveying the inseparability of mind and body, "bodymind" also reconfigures human embodiment holistically, "as fluid and as indivisibly entangled with the world, situating embodied experience as a site of knowledge" (Rice et al., 2021, p. 97).
Foucault's concept of the state's disciplinary power, which, through constant surveillance and normalizing judgement, produces "docile bodies," has directly influenced Wilks' ludonarrative ${ }^{6}$ design. Specifically, an algorithm based on a dynamic "docility value" affects the morphing appearance and behavior of the organic. The higher the docility value, the more the organic conforms to a standard symmetrical shape and its motion restricted by a restraining visible geometry. The lower the docility value, the more freeform is the shape, the more liberated its movement and the weaker the restricting geometry. The docility value is affected by programmed narrative events and, crucially, the choices the reader-player makes, who, in a feedback loop, is affected by visible changes in the organic. Furthermore, the reader-player's choices contribute to an aggregate 'DocileBody-Bearing' value which helps steer a course through the nonlinear, branching narrative.

This docility-based algorithm is an efficient way of designing a playable narrative. At the same time, however, we are uneasy about the rule of a bipolar numerical value underlying essentially nonbinary, fluid experiences. This inherent contradiction is an interesting analogy for the very issues our project aims to address. As our participants intimated, we want to resist normalization but recognize that we cannot completely escape it. We must find ways of being in the world as it is, whilst also finding ways of making changes in the world. However, we envisage that the power of narrative will have a far stronger effect than an underlying algorithm, which, after all, only assists in steering the narrative, it doesn't determine the narrative content. The richness, complexity, ambiguity and nuance of storytelling born out of the lived experiences of our research participants will override a reductive binary system, rendering the digital binary an ancillary rather than dominant element in our interactive narrative.

\section{Bodies and Bodyminds in Play}

If, as Possible Worlds narrative theory posits, the real world serves as a model for the mental construction of textual fictional story-worlds, it follows that our experience and knowledge of real bodies, including our own bodies, serve as a model for the mental construction of textual fictional bodies. Unless a text draws attention to the physical appearance of a fictional character, the reader will tend to assume, according to Ryan's "principle of minimal departure" (Ryan, 1991), that their body conforms to a familiar or generic norm (two eyes, two arms, two legs, etc.). Since this assumes a normative bodymind, we posit that what constitutes a familiar or generic norm might shift depending on the bodymind of the reader. This may be especially true for people born with disabilities for whom the disabled bodymind is their normative state (Clare, 2017). Further research with diversely-embodied readers would likely offer rich insight

\footnotetext{
${ }^{6}$ Ludonarrative: the medium-specific affordances of video game narrativity and their aesthetic and phenomenological implications for how reader-players experience narrative in games. The term was originally coined as a blend of ludology (the study of games) and narrative.
} 
into individuals' processes of constructing their imagined norms.

Potentially, due to the identification induced through diegetic enactment, the reader-player's own body model may fluidly interleave, superimpose or merge with their mental construction of the protagonist's body as they become the reader-playing-as-Hayley. Since there is no narratorial voice to assert facts about Hayley's body and it is never depicted in mimetic visual form, how the reader-player constructs her body is open to interpretation, open to (re)construction. Hayley's negative self-talk describes her as fat, flabby and repulsive, but how far is that a distortion of her body image ${ }^{7}$ ? The reader-player may decide that Hayley's Inner Critic is not a reliable source of the textual actual truth ${ }^{8}$ about her body and mentally construct her differently, perhaps, if they identify strongly with her specific body image issues, empathically shaping her in their own self-image. But what if they do not identify strongly with Hayley's particular body image issues? Since there is no authorial or manifest depiction to fix the reader-player's mental image, the reader-playing-as-Hayley may construct a shape-shifting body, drawn from a pooling or mingling of their knowledge and experience of other bodies, which may include (if not default to) normative concepts of the hegemonic standard body (white, middle-class, able-bodied, etc.). However, Hayley is the narrative's focalizing character and readers/viewers/listeners/players "relate to characters more intensely if they are focalisers" (Eder et al., 2010, p.53). Since identification is multidimensional, it does not depend on similarity. The reader-player will identify with Hayley's intentions, expectations, hopes, fears, beliefs and feelings - the cognitive, moral and emotional dimensions - and they will also identify with her actions and motions.

Because the abstract visualization of Hayley's bodymind, the organic, is animated and responsive to her thoughts it is seemingly alive and an important locus for embodied identification. Behavioral and neuroimaging studies have shown that " $[t]$ hrough embodied identification, readers mentally simulate performing the character's actions and motions" (van Krieken et al., 2017:9; also see; Gallese, 2011). Towards the end of the multilinear narrative, having experienced the vicissitudes of Hayley's (more or less) docile bodymind, eventually, the reader-player will arrive at a place where the organic is liberated from its normalizing restraints. The readerplaying-as-Hayley will find they are focusing on her body in carefree motion, rather than on how it looks. Studies have shown that focusing on body functionality (interpreted in its broadest terms to mean everything a body can do from breathing, to feeling, to thinking, to moving including how that body's capacities are enhanced and/or limited in a given sociomaterial context) can help cultivate a positive body image

${ }^{7}$ This is not to suggest that body dissatisfaction can be reduced to a simplistic binary of external reality vs internal distortion of reality

${ }^{8}$ In Possible Worlds literary theory, facts asserted by a (reliable) narrator constitute the "textual actual world," which may be at odds with what characters know or believe about the fictional world they inhabit (see Ryan, 2013).
(Rice et al., 2021, p.96). Therefore, because the reader-player will be mentally simulating this motion through identification, it could have a beneficial effect on their own body image. The effect may be strengthened by the awareness that they have arrived at this joyous moment as a result of the narrative choices they have made along the way.

\section{Interactive Narrative and Therapeutic Effects}

The literature on body image problems and body dysmorphic disorders indicates that cognitive behavior therapy (CBT) approaches are amongst the most successful therapies (Grogan, 2017; O'Connor et al., 2017). These involve some form of questioning and challenging habitual thoughts or thinking patterns. For instance, The Body Image Workbook encourages the reader to question their "Appearance Assumptions" (Cash, 2008, loc.1212), which are core beliefs concerning how someone defines themselves and their selfworth based on their looks.

In a text-based interactive narrative with a therapeutic remit, where the reader-player has direct access to the mind of the protagonist and some power to literally change her mind, a CBTinspired storytelling approach would seem to be a good fit. After all, as Palmer argues, "narrative fiction is, in essence, the presentation of fictional mental functioning" (Palmer, 2004, loc. 98). So, the interactive narrative dramatizes some CBT methods. In other words, some of Hayley's fictional experiences are modelled on CBT processes and thus the reader-player may vicariously experience their effects or, at least, become aware of CBT as a therapeutic option. For example, Hayley experiments with Mirror Exposure Therapy (a form of CBT). This was directly inspired by the many references to mirrors in the participant data and one particular participant, who wrote positively about their mirror exposure experience. However, because CBT focuses on thought, it can reinforce the mind-body split, which we want to avoid. Nor do we want to reduce the widespread problem of body dissatisfaction and the responsibility for "fixing" it to the individual. Hopefully, the intersectional cast of characters, who from time to time engage in discussion around the broader societal issues and offer casual or more politicized critiques of the effects of neoliberal consumerism, will contextualize and expand the individual-mind-centered drama. This is critically important because, following the shift in our project title, it helps to shift the locus of the problem from individuals' bodyminds to their body worlds.

The narrative's cast of characters express a range of different experiences, perceptions, thoughts and feelings about their bodies and the world they live in. They all struggle or have struggled with body dissatisfaction to some degree or other and some are more resilient than others. In The Body Image Workbook, Cash describes two groups of people: "Assumers," who tend to agree with typical "Appearance Assumptions," and "Doubters," who tend to disagree (2008, loc.1225). He found that Assumers experience far more body dissatisfaction than Doubters. Broadly speaking, the cast of characters fall into these two 
groups: Assumers and Doubters. The preoccupations, beliefs and attitudes of some characters tend to have detrimental effects on body image, whilst others have healing or protective effects. For example, some characters are ardent feminists and " $[\mathrm{r}]$ esearch has shown that women who hold feminist attitudes to body image are more satisfied than those who do not identify with feminist values" (Grogan, 2017, p.189). The interplay of Hayley's inner voices, her interactions with other characters and, on occasions, with intrusive fictional marketing messages challenge the readerplaying-as-Hayley in positive and negative ways. How normative or how empowering and liberating their effect depends on the choices the reader-playing-as-Hayley makes. The nature of the choices offered throughout the narrative include, not only decisions about what to do but also, different ways they may choose to think or feel about the matter at hand. In other words, many of the interactive choices woven through the narrative dramatize situations and enact processes influenced by CBT and feminist methods. However, the branching nature of the interactive narrative means that the "CBT route" is not the only path towards a more positive outcome that the narrative offers. Other options that the reader-playing-as-Hayley may choose to explore focus more on activism, social engagement and/or resistance.

Meanwhile, behind the scenes, the underlying ludonarrative program tracks the tendencies of the reader-playing-as-Hayley towards more normative or more liberating and empowering choices, and this affects the course they take through the branching narrative. Subtextually, the aim is to transform Hayley from an Assumer to a Doubter. The non-linear, branching narrative offers different ways of achieving this, recognizing that there is no single correct route to selfcompassion and body acceptance. Some routes may be more internally focused, others more outward-looking. In this respect, an interactive digital narrative is particularly well suited to promoting a diversity of approaches to wellbeing and social change by allowing reader-players to explore different options.

Discussing novels (or print fiction), Zunshine argues:

The cognitive rewards of reading fiction might thus be aligned with the cognitive rewards of pretend play through a shared capacity to stimulate and develop the imagination. It may mean that our enjoyment of fiction is predicated--at least in part--upon our awareness of our "trying on" mental states potentially available to us but at a given moment differing from our own. (Zunshine, 2006, loc. 327).

If this is the case, it follows that the cognitive rewards may be even more powerful in an interactive fiction that engages the reader-player in diegetic enactment, a more active form of pretend play. The reader-playing-as-Hayley is not only "trying on" mental states but also "trying on" various decision-making processes and exploring their consequences for (further) mental states involving body image. In the absence of a narrator, there is no higher authority to depend on or defer to, the reader-player must rely on their own interpretive powers and use their own judgement. Furthermore, some of the decision-making is also about taking action in the world, such as engaging in feminist social activism, so the effect of "trying on" could be beneficial or enlightening (for want of a better word) in multiple ways. As a branching narrative with a cyclic structure there is no win-lose end state in our digital fiction, there are simply different consequences for different inclinations. If they choose to cycle through other/more days in the life of the protagonist, the readerplaying-as-Hayley may "try on" the effects of different choices. This, not only avoids intrusive didacticism, but allows the digital fiction to be of potential benefit to a wider and more diverse audience.

\section{Openness and Accessibility}

In a work that prioritizes inclusive design and equitable access on both the psychological and material level, another primary concern is the accessibility of the technological medium and platform of delivery/distribution. According to the World Wide Web Foundation, the web is "a global public good and a basic right” (World Wide Web Foundation, 2021, para. 2). It is built on open standards developed and maintained by the World Wide Web Consortium (W3C), whose mission is to make the benefits of the web "available to all people, whatever their hardware, software, network infrastructure, native language, culture, geographical location, or physical or mental ability" (World Wide Web Consortium, 2021, para. 4). These aims are compatible with those of our project (although our remit is narrower, the digital fiction springs from a specific cultural background and we do not have the resources to offer it in multiple languages). Therefore, with accessibility in mind, and because our participants told us they preferred using smartphones and tablets, we chose to build the digital fiction on and for the open web platform using a mobile-first, responsive web design approach for the greatest reach. The aim is to provide a good user experience at all screen sizes and combinations of hardware and network capabilities, starting with small screens and adding enhancements that further enrich the user experience as the screen size and/or technological capabilities increase. Equally important, the digital fiction web app complies with ARIA $^{9}$ standards to make it more accessible to people with a diverse range of abilities and disabilities.

Open access is an important, guiding principle for our project but it also resonates with our aims and the content and nature of the creative work on a deeper level. The data business model behind the "walled gardens" of social media platforms involves "harvesting digital footprints from each user to get better insights into their psychological profiles and to sell these insights to marketing companies" (Montag and Hegelich, 2020). This leads the platforms to design and engineer their applications to encourage prolonged usage time and interactions, such as "comments", "shares" or "likes," which provide even more detailed data (Behrenshausen, 2018; Montag and Hegelich, 2020). This "persuasive technology" (Center for Humane Technology, 2021) is yet another layer of Foucauldian disciplinary power that aims to produce "docile bodies" in the form of users addictively maintaining their social media identities and relationships. It is no surprise, then, that the big

${ }^{9}$ Accessible Rich Internet Applications (see MDN Contributors, 2021). 
tech platforms that want to lock us into proprietary systems are amongst the most prolific purveyors of imagery and messaging that contribute to body dissatisfaction in young people (AparicioMartinez et al., 2019; de Vries et al., 2019). Whilst it is important to challenge and speak back to oppressive messaging from within the social media platforms, it is also important to resist their dominance and control by offering content on and encouraging use of the open web.

\section{CONCLUDING THOUGHTS}

Story is central to human beings because, as Thomas King writes, "The truth about stories is that's all we are" (King, 2003, p.2). According to narrative therapy, "persons generally ascribe meaning to their lives by plotting their experience into stories, and ... these stories shape their lives and relationships" (White and Epston, 1990, p.79). Sometimes those dominant stories become "problem-saturated" (White and Epston, 1990, p.16) and/or they take hold and solidify, stifling potential, incipient or alternative accounts that might, if brought forth and thickened, open new possibilities for living well. This bringing forth of new possibilities and alternative accounts becomes a "re-storying of experience" (White and Epston, 1990, p.17).

Reading narrative, whether interactive or not, is never a passive process, rather it engages the reader in "performances of meaning under the guidance of the text" (Bruner, 1986, as cited in White and Epston, 1990, p.13). When the reader identifies with the narrative, it invites self-reflection and that may help the individual identify such possibilities and alternatives for restorying their own experience.

Stories are full of gaps which persons must fill in order for the story to be performed. These gaps recruit the lived experience and the imagination of persons. With every performance, persons are reauthoring their lives. The evolution of lives is akin to the process of reauthoring, the process of persons' entering into stories, taking them over and making them their own. (White and Epston, 1990, p.13).

White and Epston's description of the interplay between story and lived experience is especially pertinent to our digital fiction, which calls for the reader-player to interactively enter the story and make meaningful narrative choices that affect the fictional character's life and may reverberate in their own life reauthoring.

Compared to older forms, such as novels, poetry and drama, choice-based interactive fiction ${ }^{10}$ is a relatively new genre that has, we propose, great potential for bibliotherapy. Our interactive digital narrative is intended to be enjoyable but the choices it offers are not just for fun: they are specifically designed to encourage the reader-player to reflect upon or think critically about body image matters.

${ }^{10}$ Choice-based interactive fiction in digital media has existed since the first text adventure games of the 1970s.
Whether faced with a comparatively minor decision or finding themselves at the crux of a major narrative turning point, each choice is meaningful and has consequences. Some will stimulate inner reflection or interpersonal musings, others will stimulate thinking about body image in relation to cultural or socio-political contexts. Individually or cumulatively, each of these narrative/dramatic moments could lead to catharsis and insight, especially because the engaged reader-player is called upon to do more than simply identify with the protagonist, they must enact her choices, causing narrative events. We anticipate that the experience will result in the reader-player realizing that what their body (Hayley's/their own) looks like is less important than how they think and feel and behave in their body. Or, to quote Kite and Kite's mantra, that they are "more than a body" (2021). This is the narrative's aim and its openness and multilinearity is a deliberate strategy to make the bibliotherapeutic benefits and socio-political commitments of the work as fluid and widely accessible as possible. These are the particular affordances of interactive digital fiction for bibliotherapy. We look forward to finding out how far this strategy is successful when we start to gather feedback from reader-players in the near future.

\section{DATA AVAILABILITY STATEMENT}

The raw data supporting the conclusion of this article will be made available by the authors, without undue reservation.

\section{ETHICS STATEMENT}

The studies involving human participants were reviewed and approved by the Research Ethics Board 1, University of Alberta. The participants provided their written informed consent to participate in this study.

\section{AUTHOR CONTRIBUTIONS}

AE, CR, SR, MP, HF, LM, and CW contributed to the conception and design of the study. MP, HF, LM, AE, CR, KB, and CW facilitated the participant research workshops. MP and CW performed the participant data analysis. CW is writing, designing and developing the digital fiction. CW wrote the first draft of the manuscript. CW, $\mathrm{AE}, \mathrm{CR}$, and $\mathrm{SR}$ wrote sections of the manuscript. All authors contributed to manuscript revision, read, and approved the submitted version.

\section{FUNDING}

The research was funded by an Insight Grant from the Social Sciences and Humanities Research Council of Canada (SSHRC IG 435-2018-1036). 


\section{REFERENCES}

Ames, D. L., Jenkins, A. C., Banaji, M. R., and Mitchell, J. P. (2008). Taking Another Person's Perspective Increases Self-Referential Neural Processing. Psychol. Sci. 19 (7), 642-644. doi:10.1111/j.1467-9280.2008.02135.x

Aparicio-Martinez, P., Perea-Moreno, A.-J., Martinez-Jimenez, M. P., RedelMacías, M. D., Pagliari, C., and Vaquero-Abellan, M. (2019). Social Media, Thin-Ideal, Body Dissatisfaction and Disordered Eating Attitudes: An Exploratory Analysis. Int. J. Environ. Res. Public Health 16 (21), 4177. doi:10.3390/ijerph16214177

Bartky, S. L. (1988). "Foucault, Femininity, and the Modernization of Patriarchal Power," in Writing on the Body: Female Embodiment and Feminist Theory. Editors K. Conboy, N. Medina, and S. Stanbury (New York: Routledge), 90-110.

Behrenshausen, B. (2018). 'What Is the Open Web?' Year of Open. Available at: https:// www.yearofopen.org/november-open-perspective-what-is-open-web/what-is-theopen-web-bryan-behrenshausen-writer-and-editor-red-hat/(Accessed January 6, 2021).

Brewster, L. (2019). CILIP Webinar Bibliotherapy GMT20190612-113322_video. Available at: https://vimeo.com/342991838 (Accessed July 30, 2021).

Brewster, L., and McNicol, S. (2020). Bibliotherapy in Practice: a Person-Centred Approach to Using Books for Mental Health and Dementia in the Community. Med. Humanities 47 (4), e12. doi:10.1136/medhum-2020-011898

Butler, J. (1997). "Performative Acts and Gender Constitution," in Writing on the Body: Female Embodiment and Feminist Theory. Editors K. Conboy, N. Medina, and S. Stanbury (New York: Columbia University Press).

Cash, T. (2008). The Body Image Workbook: An Eight-Step Program for Learning to Like Your Looks. 2Rev Ed. U.S: New Harbinger Publications.

Center for Humane Technology (2021). How Social Media Hacks Our Brains, Center for Humane Technology. Available at: https://www.humanetech.com/ brain-science (Accessed August 24, 2021).

Chandler, E., Ignagni, E., Aubrecht, K., and Rice, C. (2021). Cripistemological Approaches to Disability Arts and Culture: Reflections on Cripping the Arts Symposium. Stud. Soc. Justice 15 (2), 170-179. doi:10.26522/ssj.v15i2.2429

Cherry, K. (2021). What Is Catharsis? Verywell Mind. Available at: https://www. verywellmind.com/what-is-catharsis-2794968 (Accessed December 13, 2021)

Clare, E. (2017). Brilliant Imperfection: Grappling with Cure. Durham and London: Duke University Press.

Clarkson, J. (2003). Inclusive Design: Design for the Whole Population. London; New York: Springer.

de Vries, D. A., Vossen, H. G. M., and van der Kolk - van der Boom, P. (2019). Social Media and Body Dissatisfaction: Investigating the Attenuating Role of Positive Parent-Adolescent Relationships. J. Youth Adolescence 48 (3), 527-536. doi:10.1007/s10964-018-0956-9

Dobson, A. S. (2015). "Postfeminist Digital Cultures: Femininity, Social Media, and Self-Representation," in Critical Studies in Gender, Sexuality, and Culture (New York: Palgrave Macmillan US). doi:10.1057/9781137404206

Eder, J., Jannidis, F., and Schneider, R. (2010). "Characters in Fictional Worlds: An Introduction," in Characters in Fictional Worlds: Understanding Imaginary Beings in Literature, Film, and Other Media. Bilingual edition (Berlin; New York: Walter de Gruyter \& Co).

Ensslin, A., Rice, C., Riley, S., Wilks, C., Perram, M., Fowlie, H., Munro, L., and Bailey, K. A. (2020). “These Waves ...." Writing New Bodies for Applied E-Literature Studies | Electronic Book Review'. electronic book review, 5 April. Available at: https://electronicbookreview.com/essay/these-waveswriting-new-bodies-for-applied-e-literature-studies/(Accessed May 13, 2020).

Ensslin, A., Skains, L., Riley, S., Haran, J., Mackiewicz, A., and Halliwell, E. (2016). Exploring Digital Fiction as a Tool for Teenage Body Image Bibliotherapy*. Digital Creativity 27 (3), 177-195. doi:10.1080/14626268.2016.1210646

Fanner, D., and Urquhart, C. (2008). Bibliotherapy for Mental Health Service Users Part 1: A Systematic Review. Health Inf. Libraries J. 25 (4), 237-252. doi:10.1111/j.1471-1842.2008.00821.x

Gallese, V. (2011). Embodied Simulation Theory: Imagination and Narrative. Neuropsychoanalysis 13 (2), 196-200. doi:10.1080/ 15294145.2011.10773675

Gill, R. (2007). Postfeminist Media Culture: Elements of a Sensibility. Eur. J. Cult. Stud. 10, 20. doi:10.1177/1367549407075898
Green, K. (2020). Re-Thinking Therapeutic Literature with Dr Kelda Green. Available at: https://www.booktherapy.io/blogs/news/re-thinking-therapeuticliterature-with-kelda-green (Accessed August 4, 2021).

Green, K. (2018). When Literature Comes to Our Aid: Investigations into Psychological Understanding in the Writing of Seneca and Montaigne, Wordsworth and George Eliot. PhD thesis. Liverpool: University of Liverpool. Available at: Https://Livrepository.Liverpool.Ac.Uk/3025512/1/ 200360459_Apr2018.Pdf (Accessed August 5, 2021).

Grogan, S. (2017). Body Image: Understanding Body Dissatisfaction in Men, Women and Children. 3 edition. London: Routledge.

Hayles, N. K. (1999). How We Became Posthuman: Virtual Bodies in Cybernetics, Literature, and Informatics. 74th edition. Chicago, Ill: University of Chicago Press.

Hogue, J. V., and Mills, J. S. (2019). The Effects of Active Social Media Engagement with Peers on Body Image in Young Women. Body Image 28, 1-5. doi:10.1016/ j.bodyim.2018.11.002

Hynes, A. M. (2018). Bibliotherapy: The Interactive Process A Handbook. 1st edition. London and New York: Routledge.

Jannidis, F. (2013). "Character," in The Living Handbook of Narratology. Editor P. Hühn (Hamburg: Hamburg University). Available at: http://www.lhn.unihamburg.de/node/41.html (Accessed September 14, 2013).

Keen, S. (2006). A Theory of Narrative Empathy. Narrative 14 (3), 207-236. doi:10.1353/nar.2006.0015

King, T. (2003). The Truth about Stories: A Native Narrative. Toronto: House of Anansi Press.

Kite, L., and Kite, L. (2020). More than a Body: Your Body Is an Instrument, Not an Ornament. Boston and New York: Houghton Mifflin Harcourt.

S. McNicol and L. Brewster (Editors) (2018). Bibliotherapy (London: Facet). doi: $10.29085 / 9781783303434$

MDN Contributors (2021). ARIA - Accessibility | MDN, MDN Web Docs. Available at: https://developer.mozilla.org/en-US/docs/Web/Accessibility/ ARIA (Accessed April 29, 2021).

Mitchell, G. J., Rice, C., and Pileggi, V. (2018). Co-Emergence: An Art-Full Dance of Inquiry into Artists' Experiences of Making Art. Res. Drama Educ. J. Appl. Theatre Perform. 23 (4), 563-581. doi:10.1080/13569783.2018.1507730

Montag, C., and Hegelich, S. (2020). 'Understanding Detrimental Aspects of Social Media Use: Will the Real Culprits Please Stand up?' Front. Sociol. 5, 94. doi:10.3389/fsoc.2020.599270

O'Connor, A., Callaghan, L., and Catchpole, C. (2017). Body Image Problems and Body Dysmorphic Disorder: The Definitive Treatment and Recovery Approach. 2nd Edition. Newark, Nottinghamshire: Trigger Press.

Orbach, S. (2019). Bodies. London: Profile Books.

Palmer, A. (2004). Fictional Minds. Lincoln and London: University of Nebraska Press.

Price, M. (2015). The Bodymind Problem and the Possibilities of Pain. Hypatia 30 (1), 268-284. doi:10.1111/hypa.12127

Rice, C. (2014). Becoming Women: The Embodied Self in Image Culture. Toronto, Buffalo and London: University of Toronto Press.

Rice, C., Chandler, E., Harrison, E., Liddiard, K., and Ferrari, M. (2015). Project ReVision: Disability at the Edges of Representation. Disabil. Soc. 30 (4), 513-527. doi:10.1080/09687599.2015.1037950

Rice, C., Jiménez, K. P., Harrison, E., Robinson, M., Rinaldi, J., LaMarre, A., et al. (2020). Bodies at the Intersections: Refiguring Intersectionality through Queer Women's Complex Embodiments. Signs: J. Women Cult. Soc. 46 (1), 177-200. doi:10.1086/709219

Rice, C., LaMarre, A., and Mykitiuk, R. (2018). "Cripping the Ethics of Disability Arts Research," in Handbook of Ethics in Critical Research: Stories from the Field. Editors C. Macleod, J. Marx, P. Mnyaka, and G. Treharne (London: Palgrave), 257-272. doi:10.1007/978-3-319-74721-7_17

Rice, C., Riley, S., LaMarre, A., and Bailey, K. A. (2021). What a Body Can Do: Rethinking Body Functionality through a Feminist Materialist Disability Lens. Body Image 38, 95-105. doi:10.1016/j.bodyim.2021.03.014

Riley, S., Evans, A., and Robson, M. (2018). "PostFeminism and Health: Critical Psychology and Media Perspectives," in Critical Approaches to Health. 1st Edition (London: Routledge).

Ryan, M.-L. (2013). "Possible Worlds," in The Living Handbook of Narratology. Editor P. Hühn (Hamburg: Hamburg University). 
Available at: http://www.lhn.uni-hamburg.de/article/possible-worlds (Accessed May 26, 2015).

Ryan, M.-L. (1991). Possible Worlds, Artificial Intelligence and Narrative Theory. 1st Edition. Bloomington: Indiana University Press.

The Reader (2021). Our Impact, the Reader. Available at: https://www. thereader.org.uk/what-we-do/our-impact/ (Accessed August 10, 2021).

Troscianko, E. (2018). Literary Reading and Eating Disorders: Survey Evidence of Therapeutic Help and Harm. J. Eat. Disord. 6, 8. doi:10.1186/s40337018-0191-5

van Krieken, K., Hoeken, H., and Sanders, J. (2017). Evoking and Measuring Identification with Narrative Characters - A Linguistic Cues Framework. Front. Psychol. 8, 1190. doi:10.3389/fpsyg.2017.01190

White, M., and Epston, D. (1990). Narrative Means to Therapeutic Ends. First Edition. New York: W. W. Norton \& Company.

Wilks, C. (2020). Stitched up in the Conversengine: Using Expressive Processing and Multimodal Languages to Create a Character-Driven Interactive Digital Narrative. PhD thesis. Bath: Bath Spa University.

Wilks, C. (2021). Writing New Body Worlds. Crissxross. Available at: https://crissxross. net/projects/writing-new-body-worlds (Accessed October 1, 2021).

World Wide Web Consortium (2021). W3C Mission. W3C. Available at: https://www. w3.org/Consortium/mission (Accessed April 14, 2021).
World Wide Web Foundation (2021). Sir Tim Berners-Lee, World Wide Web Foundation. Available at: https://webfoundation.org/about/sir-tim-berners-lee/ (Accessed April 29, 2021).

Zunshine, L. Z. L. (2006). Why We Read Fiction: Theory of the Mind and the Novel. Columbus: Ohio State University Press.

Conflict of Interest: The authors declare that the research was conducted in the absence of any commercial or financial relationships that could be construed as a potential conflict of interest.

Publisher's Note: All claims expressed in this article are solely those of the authors and do not necessarily represent those of their affiliated organizations, or those of the publisher, the editors and the reviewers. Any product that may be evaluated in this article, or claim that may be made by its manufacturer, is not guaranteed or endorsed by the publisher.

Copyright (ङ 2022 Wilks, Ensslin, Rice, Riley, Perram, Bailey, Munro and Fowlie. This is an open-access article distributed under the terms of the Creative Commons Attribution License (CC BY). The use, distribution or reproduction in other forums is permitted, provided the original author(s) and the copyright owner(s) are credited and that the original publication in this journal is cited, in accordance with accepted academic practice. No use, distribution or reproduction is permitted which does not comply with these terms. 